\title{
AS TECNOLOGIAS DA INFORMAÇÃO E O ENSINO DE MATEMÁTICA NA ESCOLA PÚBLICA: PRÁTICAS PRESENTES E PERSPECTIVAS FUTURAS
}

\section{THE INFORMATION TECHNOLOGIES AND THE MATH TEACHING IN THE PUBLIC SCHOOL: PRESENT PRACTICES AND FUTURE PERSPECTIVES}

Fernando Henrique Neves, José Jailton da Cunha, Maria Lucineide Dioginis, Nívea Cristina Lucindo, Wílson Cristovam

Universidade San Carlos - USC, Programa de Pós-Graduação em Ciências da Educação, Assunção, Paraguai.

E-mail: postgrado@sancarlos.edu.py

RESUMO - O objetivo deste estudo foi analisar as contribuições das Tecnologias da Informação e Comunicação (TICS) como recurso auxiliar nas aulas de matemática, especificamente no processo de ensino. Assim, o presente trabalho refletiu sobre a utilização das TICs visando melhorar o desenvolvimento do processo de ensino e aprendizagem nas escolas pública do Município de Mirante do Paranapanema - SP. A metodologia utilizada na pesquisa constou de cunho qualitativa, devido à sua abrangência e à vantagem de proporcionar ao pesquisador o contato direto com o ambiente e com a situação que está investigando. Os resultados foram compreender a necessidade de investir na formação dos professores, considerando o aluno como construtor do conhecimento e o professor mediador da aprendizagem. Concluímos que alunos e professores tem consciência de que os recursos tecnológicos tornam as aulas desafiadoras e significativas. No entanto, a fragmentação da formação continuada dificulta a implementação efetiva das TICs em sala de aula.

Palavras-chave: Tecnologia de Informação e Comunicação; Abordagem Construcionista; Aprendizagem Significativa; Formação Continuada de Professores; Matemática.

ABSTRACT - The objective of this study was to analyze the contributions of technology and communication information (CIT) as auxiliary resource for the math classes, specifically in the teaching process. Therefore, the present study reflected about the utilization of CIT aiming the improvement of the development of learning process in the public school in city of Mirante do Paranapanema in São Paulo

Recebido em: 12/08/2015 Revisado em: 25/08/2015 Aprovado em: 28/08/2015 state. The methodology used in this study was the qualitative due to its coverage and advantage in provide to the researcher the direct contact with the environment and with the situation of their investigation. The results were to understand the necessity of investing in the continued study of teachers, considering the students as 
builders of their knowledge and the teacher as the mediator in this process. We concluded that students and teachers are awareness the technological resources make the classes meaningful and rewarding. However, the fragmentation of continued education makes it difficult to the implementation of CIT in the classroom.

Keywords: Technology of Information and Communication; Constructionist Approach; Meaningful Learning; Continued Study of Teachers; Math. 


\section{INTRODUÇÃO}

Este artigo é um recorte da dissertação de mestrado intitulada "As tecnologias da informação e o ensino de Matemática na escola pública: práticas presentes e perspectivas futuras". A pesquisa de mestrado foi desenvolvida no âmbito do Programa de Pós-Graduação em Ciências da Educação da Universidade San Carlos (USC) e inserida na linha de pesquisa "Tecnologia educativa e formação de professores".

Nos dias atuais, um dos temas cruciais da educação se refere ao desempenho dos alunos em Matemática. Esse desempenho é alvo de inúmeras discussões nos meios acadêmicos, especialmente em relação ao processo de ensino e aprendizagem. Assim, o baixo desempenho dos alunos em Matemática merece atenção especial e aponta para uma realidade com múltiplas faces.

A essas constatações, agrega-se o fato de que os recursos tecnológicos são usados de forma descontextualizada, isto é, as atividades e objetivos da utilização dos referidos recursos não estão em sintonia com a vivência e a realidade do aluno.

$\mathrm{Na}$ perspectiva de contribuir com a mudança dessa realidade, realizamos este estudo, selecionando professores e alunos de duas escolas da rede pública estadual do Estado de São Paulo, sendo que uma delas se encontra localizada na cidade de Mirante do Paranapanema e a outra no distrito de Costa Machado. As escolas serviram como fonte de investigação para a análise dos dados coletados e selecionados.

Neste sentido, buscamos colher informações a respeito da exploração do uso dos recursos tecnológicos nas aulas de Matemática por parte dos professores e ao mesmo tempo, identificar, se para os alunos o modelo de aula utilizando os recursos tecnológicos se torna mais significativo do que o modelo trabalhado em sala de aula comum.

Empenhamo-nos em aplicar um questionário que viesse a valorizar as potencialidades de cada indivíduo e ao mesmo tempo identificar as facilidades e dificuldades encontradas para utilizarem os recursos tecnológicos. Realizamos a análise dos resultados e conclusões com vistas à identificação do conhecimento dos professores e dos alunos a respeito de softwares matemáticos, bem como, habilidades e interesses.

O objetivo deste estudo foi analisar as contribuições das Tecnologias da Informação e Comunicação (TICs) como recurso auxiliar nas aulas de matemática, especificamente no processo de ensino. 


\section{CAMINHOS METODOLÓGICOS}

Seguindo os rigores devidos aos questionamentos, as entrevistas e as autorizações, esta pesquisa foi submetida e aprovada pela Comissão de Ética da Universidade San Carlos, conforme autorização da Resolução Número 27/10.

A pesquisa, caracterizada como qualitativa do tipo estudo de caso, foi desenvolvida através de entrevistas semiestruturadas, de estrutura flexível, pois, como afirmam Bogdan e Biklen (1994, p.17), esse tipo de entrevista possibilita que o investigador "compreenda com bastante detalhe, o que é que professores, diretores e estudantes pensam e como desenvolveram seus quadros de referência". Para a investigação a respeito desse contexto, fizemos uso de questionários que foram respondidos por professores e alunos.

O trabalho foi iniciado com estudos bibliográficos sobre o tema para a construção do referencial teórico e com uma pesquisa de campo de natureza qualitativa sobre o cotidiano de duas escolas públicas da rede estadual de ensino da cidade de Mirante do Paranapanema, que dispõe de salas de informática.

Realizamos fichamento destacando-se resultados de pesquisas feitas pelos autores como, Baranauskas (1993), Valente (2002), Papert (1985), dentre outros. Essa investigação contou com a utilização de técnicas, tais como: da observação, da entrevista e do questionário, para verificar como, quando, em que situação os professores e alunos recorrem aos recursos tecnológicos, quais as dificuldades enfrentadas na sua aplicação e, em casos de não utilização, porque não o fazem.

A última etapa desta pesquisa consistiu na tentativa de encontrar os princípios subjacentes ao fenômeno estudado e de situar as várias descobertas em um contexto mais amplo, para que pudesse ter um processo de envolvimento do pesquisador confrontando as evidências positivas e negativas com as teorias existentes para gradativamente desenvolver a sua própria teoria (LÜDKE; ANDRÉ, 1986), fundamentado nos conhecimentos teóricos de diferentes autores.

Ao analisar os resultados com a aplicação dos questionários aos cinco professores e 167 alunos selecionados, revelou-se que a abordagem aplicada para utilização do computador ainda é instrucionista. No entanto, salientamos que a abordagem construcionista é a mais adequada, pois considera, a partir da mediação do professor, o aluno como construtor de seu conhecimento (VALENTE, 1999). 


\section{APRESENTAÇÃO E ANÁLISE DOS DADOS}

Com base nos pressupostos teóricos estudados, tivemos a cautela de olhar para cada resposta coletada da forma mais coerente possível, criando um espaço para perceber a forma como o ensino de Matemática era pensado para as escolas pesquisadas e que estratégias poderiam ser utilizadas para aprimorar esse processo.

Analisando as respostas dos alunos em relação aos interesses durante a utilização do computador e da internet, verificamos em praticamente todos os casos pesquisados a referência a pesquisas, jogos e redes sociais, com destaque para o acesso a vídeos e imagens, especialmente os que são disponibilizados pelo Youtube e Google.

Sobre o uso e conhecimento de algum software matemático, todos os alunos disseram desconhecer e não utilizar. Mencionaram, no entanto, a pesquisa ao Caderno do aluno. A mesma unanimidade é percebida no que se refere às dificuldades enfrentadas nos laboratórios de informática da escola: todos os alunos mencionaram a falta de computador e a falta de tempo disponível para pesquisas na internet.

Sobre a contribuição que o uso de tecnologias pode oferecer ao processo de aprendizagem, a maioria dos alunos mencionou que a utilização do Datashow nas aulas permite visualizar imagens, figuras geométricas, vídeos relacionados com o assunto, tornando assim as aulas mais interessantes ("mais legais", "mais fáceis de entender"). Além disso, mencionaram a possibilidade de aprender coisas novas e de se manterem atualizados. Da mesma forma, comentaram que as tecnologias tornam as aulas mais divertidas, estimulam a memória e o trabalho mental, como também facilitam o entendimento do assunto abordado.

De um modo geral, a partir dos dados coletados e sistematizados, é possível observar por meio das respostas dos alunos que o uso dos recursos tecnológicos vem sendo trabalhado de tal forma que não contempla os aspectos pedagógicos que compõem a proposta de formação. Contudo, para a formalização dessa proposta de formação explorando os aspectos pedagógicos, há necessidade de mudanças na postura do professor, tais como: refletir e revisar a sua prática pedagógica, ser capaz de acompanhar o processo de aprendizagem dos seus alunos, saber articular os conteúdos curriculares com o uso das TICs.

Começamos nossa pesquisa na escola com a hipótese de que os métodos adotados pelo professor para utilizar o computador no processo de ensino e aprendizagem seriam métodos instrucionistas, que concebem o computador como máquina de ensinar e os alunos como recipientes vazios, que assimilam somente aquilo que a atividade propõe, sem que haja reflexão, depuração, 
ou a oportunidade de se construir o próprio conhecimento (VALENTE, 1993).

A confirmação dessa hipótese se deu a partir da análise das respostas dos professores que também foram coletadas com a aplicação dos questionários. Com essa confirmação, a presente pesquisa se justificava, pois não era objetivo apenas diagnosticar a situação do uso do computador no contexto escolar focado no processo de ensino e aprendizagem, mas sim, analisar se a utilização do computador estava acontecendo de forma ativa e reflexiva, se professores e alunos tinham conhecimento das potencialidades que os recursos tecnológicos oferecem, e se os professores haviam mudado sua prática e a forma de ensinar a partir do uso dos recursos que o computador disponibiliza.

\section{DISCUTINDO OS RESULTADOS}

Consideramos que a maneira como vem sendo usados os recursos tecnológicos, não esta sendo estimulada a aprendizagem dos alunos, pois os professores não fazem uso de um software matemático e nem trabalham com atividades que permitam que ocorra a compreensão de um determinado conceito matemático. Este fato ocorre porque os professores se sentem inseguros, pois alegam uma fragmentação na formação continuada, conforme verificamos na análise dos questionários.
Foi notório observar que a maioria dos alunos entrevistados não vê o computador como uma ferramenta pedagógica que possa auxiliá-los em suas atividades educacionais, ou seja, eles veem o computador como uma ferramenta que os leva apenas ao divertimento. Assim podemos observar que o trabalho realizado com esses alunos não os conduzem a enxergar o computador como uma ferramenta que poderá levá-los ao divertimento, unindo teoria e prática a partir de um ambiente Construcionista Contextualizado e Significativo (CCS), que possibilita ao aluno uma aprendizagem mais atraente e até mesmo divertida.

De acordo com Neves (2012), para mudar o paradigma da abordagem instrucionista é necessário propor atividades contextualizadas e planejadas a partir de um ambiente Construcionista Contextualizado e Significativo (CCS), que possibilita ao aluno meios para uma aprendizagem mais atraente e até mesmo divertida.

Por outro lado, foi possível observar que alguns alunos mencionam ferramentas de pesquisas e até jogos educativos que servem de apoio para realização das atividades. No entanto, compreendemos que os alunos se interessam por uma aprendizagem fundamentada no manuseio do computador. 
Acreditamos que os professores ainda vivem na ilusão de que apenas colocar o aluno diante de uma atividade qualquer no computador garantirá que está fazendo um trabalho diferenciado, mediado pela tecnologia. Sobre essa questão, Barreto (2005, p.142) assinala que "é possível afirmar que o discurso educacional tem incorporado as TIC como modo de agregar novas possibilidades a processos pedagógicos".

Esta visão afirma que o computador por si só não faz nada: é o professor, mediador da aprendizagem, quem pode fazer a diferença, promovendo uma aprendizagem significativa para os alunos, a partir da construção de um ambiente CCS propício para o desenvolvimento de conceitos e conhecimentos. Sem essa mediação, o uso do computador será apenas um passatempo, cheio de atividades descontextualizadas que podem provocar a desmotivação do aluno.

Entretanto, ressaltamos que, para o professor fazer uso dos recursos que o computador disponibiliza de forma dinâmica e significativa, se faz necessário uma proposta de formação continuada.

Logo, considerando o fato de que na escola devem ocorrer mudanças para a utilização de todo potencial do computador, Valente (1999) complementa tal afirmativa.

O uso do computador na
criação de ambientes de
aprendizagem que enfatizam
a construção do
conhecimento apresenta

enormes desafios. Primeiro, implica em entender o computador como uma nova maneira de representar o conhecimento. Segundo, requer a análise cuidadosa do que significa ensinar e aprender, bem como demanda rever o papel do professor nesse contexto. Terceiro, a formaçao desse professor envolve muito mais do que prover o professor com conhecimentos sobre computadores.

Nesse sentido, entendemos que uma das estratégias que poderia ser aplicada como forma de atender as necessidades desses professores seria cursos de formaçao continuada que proporcionasse condições para o professor construir conhecimentos sobre as técnicas computacionais e entender por que e como integrar o computador em sua prática pedagógica.

Diante desse contexto, acreditamos que uma formaçao continuada que englobe essas características seja a mais indicada para trabalhar com os recursos tecnológicos tendo como objetivo sanar as dúvidas que geram nos professores mediante a utilizaçao desses recursos. Contudo, o que temos visto em muitos estados e municípios é a implementaçao de projetos e cursos de formaçao complementar do professor que não têm uma relação direta com os problemas que ele enfrenta ao fazer ou ao tentar fazer uso do computador na escola e, nesse caso, pouco contribuem para o fazer pedagógico e para a apropriaçao de novos 
conceitos sobre o ensino e a aprendizagem, tanto de matemática como de um modo geral.

Assim, Valente (1999) acrescenta que

O preparo do professor não pode ser uma simples oportunidade para passar informações, mas deve propiciar a vivência de uma experiência. É o contexto da escola, a prática dos professores e a presença dos seus alunos que determinam o que deve ser abordado nos curso de formaçao. Assim o processo de formaçao deve oferecer condições para o professor construir conhecimento sobre as técnicas computacionais $\mathrm{e}$ entender por que e como integrar o computador na sua prática pedagógica.

Entretanto, ao reconhecermos que a formaçao do professor não se finda na formaçao inicial e que os desafios do trabalho pedagógico geram outras necessidades formativas, a formaçao continuada assume um papel decisivo para suprir algumas dificuldades decorrentes da prática pedagógica. Acreditamos ainda que este processo de formaçao do professor deve ser repensanda, levando em consideração os saberes dos professores e as suas necessidades.

Considerando que o espaço da escola está intrinsecamente relacionado à formação contínua dos professores, Nóvoa (1997) acrescenta que o desenvolvimento pessoal, profissional, humano e organizacional da escola são fatores da profissão docente. Tardif (2000, p.07) fundamenta essa proposição ao considerar que os conhecimentos "[...] são evolutivos e progressivos e necessitam, por conseguinte, uma formação contínua e continuada, dado que o processo de constituição de saberes e aprendizagem da docência não se findam na formaçào inicial.

Assim, concordamos com Tardif (2000), ao demonstrar que não podemos confundir os saberes dos professores com os transmitidos em sua formaçao acadêmica, ou seja, aqueles adquiridos no decorrer da licenciatura.

\section{CONSIDERAÇÕES FINAIS}

Este estudo permitiu identificar e analisar a prática de professores que ensinam Matemática no Ensino Fundamental articulando o processo de ensino dessa disciplina e a utilização de TICs em sala de aula, e refletindo sobre as concepções e conceitos que circundam essa interrelação; a informática e o uso do computador nas aulas; e, também, a formação de professores de Matemática para uma prática docente diferenciada, mediada pelos recursos do computador.

Pensando na melhoria da formação do professor, observou-se que o professor necessita de respaldo teórico e prático, bem como conhecimento dos recursos que podem 
Ihe auxiliar, promovido por meio de cursos de aprimoramento que irão ajudá-lo a resolver as situações específicas com as quais está lidando em sala de aula. Somente assim poderá conduzir de maneira verdadeiramente satisfatória as aulas que ministra, auxiliando a aprendizagem dos alunos.

No entanto, faz-se necessário compreender que apenas a introdução das TICs na educação, não garante que a aprendizagem acontecerá ou que contribuirá para a prática docente. É preciso entender que o computador constitui um recurso tecnológico com potencialidades pedagógicas e com alternativas dinâmicas que podem propiciar práticas docentes diferenciadas na educação. Dessa forma, seu uso precisa ser baseado na abordagem construcionista, a partir de ambientes de aprendizagem CCS, permitindo a construção de conhecimentos que sejam contextualizados com a realidade dos alunos e significativos para a sua aprendizagem.

Em suma, diante dos estudos bibliográficos realizados e dos resultados obtidos neste trabalho, acredita-se que esta investigação promoverá o surgimento de discussões significativas a respeito do uso das TICs na educação e dos recursos do computador no processo de ensino, na formação de professores, bem como práticas educacionais em geral. Dessa forma, pode-se concluir que a formação continuada de professores se constitui de forma insuficiente e aligeirada (TEDESCO, 1998), não sendo capaz de suprir as necessidades diante do novo contexto, que exige dos profissionais uma série de capacidades e habilidades que não estavam presentes nos cursos de formação inicial, como o caso da articulação da teoria e da prática e sobretudo as especificidades do trabalho com as TICs.

\section{REFERÊNCIAS}

BARRETO, R. G. A presença das tecnologias. In: FERRAÇO, C.E. (Org.) Cotidiano escolar, formação de professors (as) e currículo. São Paulo: Cortez, 2005.

BARANAUSKAS, M. C. C.. Procedimento, função, objeto ou lógica: linguagens de programação vistas pelos seus paradigmas. In: VALENTE, José Armando, Org. Computadores e conhecimento: repensando a educação. Campinas, NIED/UNICAMP, 1993. p.45-63

BOGDAN, R. C.; BIKLEN, S. K. Investigação qualitativa em educação. Portugal: Porto Editora, 1994.

LUDKE, M.; ANDRÉ, M. E. D. A. Pesquisa em educação: abordagens qualitativas. São Paulo: E.P.U, 1986.

NEVES, F. H. As tecnologias da informação e o ensino de matemática na escola pública: práticas presentes e perspectivas futuras. 2012. 110f. Dissertação (Mestrado em Ciências da Educação) - Universidade San Carlos, Assunção - PY.

NÓVOA, A. Os professores e a sua formação. Lisboa: Dom Quixote, 1997. p.15-34. 
PAPERT, S. LOGO: computadores e educação. São Paulo: Brasiliense, 1985, p. 35-57.

TARDIF, M. Saberes profissionais dos professores e conhecimentos universitários: elementos para uma epistemologia da prática profissional dos professores e suas conseqüências em relação à formação para o magistério. Revista Brasileira de Educação. Jan/Fev/Mar/Abr, n. 13, 2000.

TEDESCO, J. C. O novo pacto educativo: educação, competitividade e cidadania na sociedade moderna. São Paulo: África, 1998.

VALENTE, J. A. (Org.). O Computador na Sociedade do Conhecimento. Campinas, SP: UNICAMP -NIED, 1999.

VALENTE, J. A. A informática na educação: o computador auxiliando o processo de mudança na escola. Campinas: Unicamp/NIED, 1999a.

VALENTE, J. A. A Espiral da Aprendizagem e as Tecnologias da Informação e Comunicação: Repensando Conceitos. In: Maria Cristina R. Azevedo Joly (Org.). A Tecnologia no Ensino: Implicações para a Aprendizagem. São Paulo: Casa do Psicólogo, 2002, p. 15-37. 